\title{
Global challenges as inspiration: A classroom strategy to foster social responsibility
}

\author{
Linda Vanasupa, ${ }^{\alpha}$ Lynn Slivovsky ${ }^{\beta}$ and Katherine C. Chen $^{\alpha}$ \\ ${ }^{\alpha}$ Materials Engineering Department, ${ }^{\beta}$ Electrical Engineering Department, \\ California Polytechnic State University, USA
}

Keywords: social responsibility, global issues, accreditation, curricula, ethics

\begin{abstract}
Social responsibility is at the heart of the Engineer's Creed embodied in the pledge that we will "dedicate [our] professional knowledge and skill to the advancement and betterment of human welfare...[placing] public welfare above all other considerations." However, half century after the original creed was written, we find ourselves in a world with great technological advances and great global-scale technologically-enabled peril. These issues can be naturally integrated into the engineering curriculum in a way that enhances the development of the technological skill set. We have found that these global challenges create a natural opportunity to foster social responsibility within the engineering students whom we educate. In freshman through senior-level materials engineering courses, we used five guiding principles to shape several different classroom activities and assignments. Upon testing an initial cohort of 28 students had classroom experiences based on these five principles, we saw a shift in attitude: before the experience, $18 \%$ of the cohort viewed engineers as playing an active role in solving global problems; after the experiences, $79 \%$ recognized the engineer's role in solving global-scale problems. In this paper, we present how global issues can be used to stimulate thinking for socially-responsible engineering solutions. We set forth five guiding principles that can foster the mindset for socially responsible actions along with examples of how these principles translate into classroom activities.
\end{abstract}

An earlier version of this paper was presented at the 2005 conference, Ethics and Social Responsibility in Engineering and Technology, Linking Workplace Ethics and Education, co-hosted by Gonzaga University and Loyola Marymount University, Los Angeles, CA, USA, 9-10 June 2005.

Addresses for correspondence: Linda Vanasupa, Materials Engineering Dept., California Polytechnic State University, San Luis Obispo, California 93407; email: lvanasup@calpoly.edu;

Lynn Slivovsky, Electrical Engineering Dept., California Polytechnic State University, San Luis Obispo, California 93407; email: 1slivovs@calpoly.edu;

Katherine C.Chen, Materials Engineering Dept., California Polytechnic State University, San Luis Obispo, California 93407; email: kcchen@calpoly.edu. 


\section{INTRODUCTION}

The engineering profession plays a critical role within society. The National Society of Professional Engineer ethics creed, states that “...I dedicate my professional knowledge and skill to the advancement and betterment of human welfare." $(1957)^{1}$ Like many other professional society ethics statements, engineers identify service to humankind as their greater purpose. In other words, social responsibility lies at the core of the engineering profession. By social responsibility, we mean the responsibility of engineers to carefully evaluate the full range of broader impacts of their designs on the health, safety and welfare of the public and the environment. This requires an evolution in students' thinking from what Kohlberg called the "conventional" stage of moral development to the "post-conventional". ${ }^{2}$ At this higher stage of moral development, the individual recognizes his connection to and interdependence on others in society. However, almost half a century after the creed was adopted, we find ourselves in a situation of great danger: the biosphere and its shrinking number of species have sustained irreparable damage. Technology (and the individuals who developed it) enabled much of this destruction, primarily through an incomplete assessment of the societal, ethical, health and safety, environmental, political and sustainability issues associated with the technology; a lack of systems thinking. In short, we technologists and our employers have not, on the whole, acted in socially responsible ways. Although engineers have made great strides in improving human welfare, the fact that the earth's ecosystem is being damaged at a rate that exceeds the earth's capacity to recover forces engineering educators to ask themselves why the critical value of social responsibility has often been compromised within the engineering profession.

We propose that socially responsible action requires at least three key attributes: the ability to act, a willingness to act, and the awareness of needs. For an engineer, the ability to act translates into technical competence, the focal point of most engineering curricula. The latter two attributes are not usually emphasized within engineering curricula. Yet, the ability to act cannot translate into action that is socially responsible without willingness and awareness. If we expect engineers to act in a socially responsible manner, we as engineering educators will need to look beyond the technical competence and simultaneously foster these other attributes.

When faced with the task of adding new learning outcomes to curricula, the first question that is raised is "What will I eliminate from the curriculum?" Fostering these other attributes can be done through changes in the way in which curricular material is presented, rather than wholesale replacements of large portions of the traditional engineering curricula. It begins by raising students' awareness of needs and the engineer's role in society. The awareness can be converted to action on the part of the engineering practitioner by guiding principles. We believe that these guiding principles can help the practicing engineer design solutions that are more socially responsible. In this paper, we discuss how the global issues can be used to raise awareness, the guiding principles and examples of how we have used them in courses. At this point, we have not fully assessed the effect of our activities. We offer these ideas for engineering educators, since our preliminary assessments have been promising. 


\section{GLOBAL CHALLENGES AS INSPIRATION}

Although there is no consensus on the exact timeline, many well-recognized scientific leaders believe that the global community is destined for a catastrophic energy and environmental crisis within this century if leading industrialized nations do not take immediate steps to radically decrease the rate at which human activity damages the biosphere. According to Wackernagel et al., the global population is currently consuming natural resources at a rate of $120 \%$ of what the earth can regenerate. ${ }^{3}$ David Goodstein, professor of physics and provost of Cal Tech, assesses the present state of fossil fuel reserves and predicts that we will deplete the earth's fossil fuels within the next 40-100 years. ${ }^{4}$ Our propensity for consuming fossil fuels has accelerated the melting of the polar ice caps within the last 20 years, aggravated by the rapid accumulation of atmospheric greenhouse gases. ${ }^{5}$ Because we have already damaged key components of the biosphere such as forests, waterways, fisheries and the ozone layer, we cannot forestall action. Indeed, over 300 university presidents have underscored the urgency of change by signing the Talloires Declaration. ${ }^{6}$ In it, university leaders call attention to the precarious state of the environment and global society, as all life and activity in the biosphere depends critically on a healthy environment. The Talloires Declaration calls for immediate action, including developing and deploying environmentally preferable technologies, to ensure a more sustainable future for all humanity. As David W. Orr states in his book Earth in Mind: On Education, Environment and the Human Prospect, "No generation has ever faced a more daunting agenda." In short, the global community is facing a crisis.

Because engineers are naturally oriented toward solving problems, these global challenges can serve as inspiration to the many young people who desire to make a difference in the world. In fact, many of the problems (such as the excessive annual generation of greenhouse gases) are intimately linked to technology. However, without a set of guiding principles, the knowledge of these large-scale problems becomes a frustrating burden. With guiding principles, students' global awareness can translate into socially responsible action.

\section{PRINCIPLE 1: EVERYTHING IS CONNECTED}

The physicist Fritjof Capra, in his book, The Hidden Connections: A Science for Sustainable Living, ${ }^{8}$ advances the idea that all of what we call "life on earth" can be considered a series of interacting systems. He also provides reference to the research developments that force scientific leaders to conclude that things are now what we had once believed; at all levels, life depends on interactions with its surroundings. The implication is that we must no longer view things, such as engineered product, in a vacuum because everything is connected. This simple law of nature is underscored by many of the global challenges that we currently face. For example, global climate change can be directly linked to the excessive consumption of carbon-based fuels.

The fact that everything is connected can be introduced into the classroom by an introduction to the engineering ethics creed coupled with a reflection exercise. A reflection exercise is simply a question that requires students to reflect upon their 
attitudes or beliefs. It has the effect of making the larger issues more personal and subsequently more meaningful. In other words, they as individuals are part of the connected web of people that we commonly refer to as society. The objectives of an assignment like this are to educate the student about the role of engineers in society, to personalize the role to them in the hope of inspiring them to embrace the role of service to human welfare. Examples of appropriate reflection questions are "What do you see as your role in society?" or "What do you plan to contribute to society during your career as an engineer?"

Another method that can be used to emphasize the systems nature is to utilize graphical depictions of events and patterns, such as causal loop diagrams. System dynamics practitioners promote the use diagrams to enable one to see a visual map of the interrelationships ${ }^{9,10}$ Figure 1 is a causal loop that depicts the reinforcing process that leads to attrition from materials engineering (MATE). A causal loop diagram depicts the interrelationship between events. The "S" indicates a change in the same direction; an "O" indicates a change in the opposite direction. Figure 1 indicates how a host of factors influence the attrition from the MATE program. For example, if their mastery in their courses increases, their morale goes up (i.e., it changes in the same direction); that causes their friendships within the MATE peers to increase; decreases their interest in a non-MATE major; increases their interest in MATE; increases their motivation; and in turn increases their mastery. This is what is knows as a reinforcing loop. One could have the students create a causal loop diagram for a global challenge such as the problem of electronic waste. An engineering instructor could have the students research or review the global problem caused by electronic waste ${ }^{11}$ and have the students map a causal loop diagram that explains how the problem develops and is perpetuated.

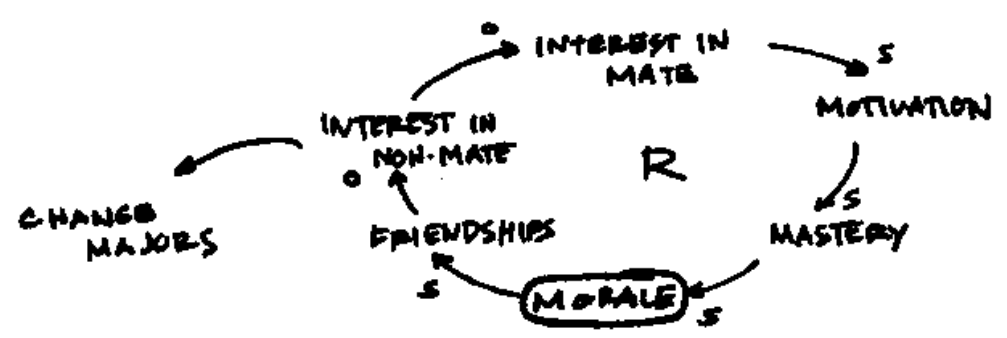

Figure 1. Reinforcing causal loop that depicts the process of leaving materials engineering (MATE). The " $\mathrm{S}$ " indicates changes in the same direction, where an "O" indicates changes in opposite directions. For example, when the mastery of the material goes up, student morale also goes up.

\section{PRINCIPLE 2: EARTH IS A CLOSED THERMODYNAMIC SYSTEM}

Thermodynamics is a subject which engineers study as part of their engineering science core. Oftentimes the examples that are used to describe the difference between open, closed and isolated systems are those with which students have very little direct 
experience, such as a calorimeter. The advantage of using these "text book" systems is that they are simplified versions of reality which fit clearly within the open, closed or isolated thermodynamic system models. One disadvantage is that two very important facts and their implications are lost: 1. the "surroundings" is the earth (usually); 2 . the earth is itself an essentially closed thermodynamic system; implication: any matter extracted from the earth cannot be replaced, any matter emitted into the earth cannot be removed. In other words, the engineering solution becomes isolated from "reality" as are the impacts of the engineering solution on the larger system.

In the classroom, the instructor can present the ideas of thermodynamic systems and require the students to determine which category the earth fall into. This can be followed by an exercise in which students are educated on the issue of global climate change and its origins and asked to come up with strategies to offset the trend of increasing carbon dioxide in the atmosphere. If these exercises are done early in the engineering curriculum, students will be more aware of the closed-system nature of earth in other designs.

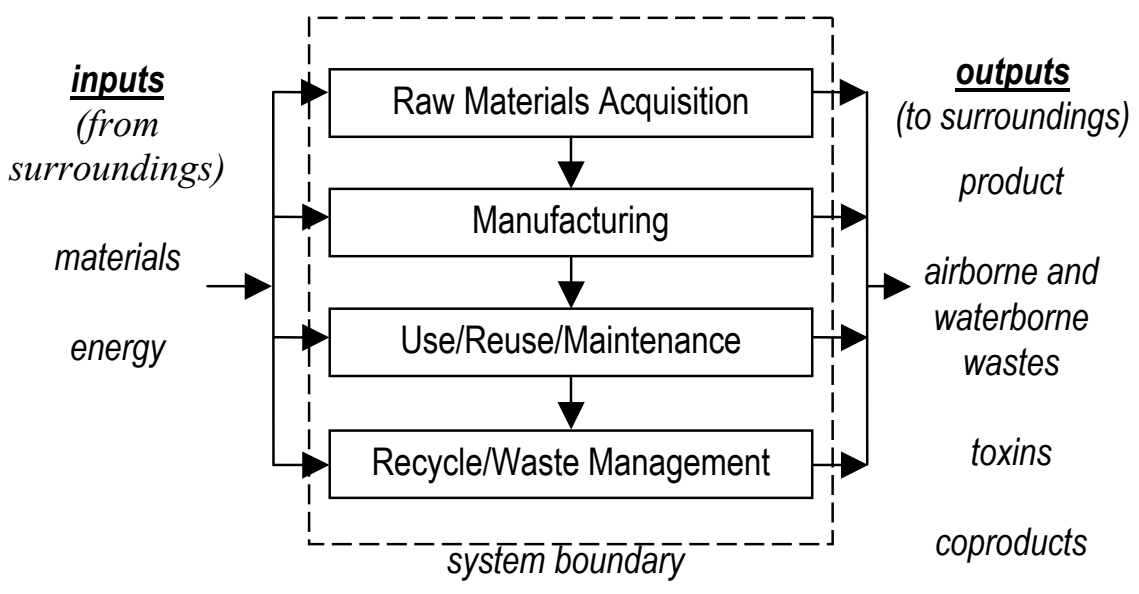

surroundings $=$ the environment

Figure 2. Life cycle stages. Adapted from U.S. Environmental Protection Agency (ref. 11).

Another way in which to emphasize the closed-system nature of earth is to present the idea of the entire product life cycle when discussing design. For example, when we spoke about designing the system in our freshman course, we presented a graphic and discussed the entire life cycle, based on the convention proposed by the United States Environmental Protection Agency. ${ }^{12}$ This convention for life cycle assessment, shown in Figure 2, reminds students that designing a product involves extractions from the environment ("surroundings") and emissions to the environment throughout the product life cycle. In this same course, we discussed the fact that the earth is essentially a closed system. This enabled the students to more fully understand the impact of their design decisions. 


\section{PRINCIPLE 3: MAKE RESPONSIBLE CHOICES EARLY IN THE DESIGN PHASE}

The best time in which to make intelligent choices is early in the design phase. Rather than creating a peripheral problem that needs to be solved, engineers should ensure that designs are inherently benign as advocated by Anastas and Zimmerman in their " 12 Principles of Green Engineering." ${ }^{\prime 13}$ One of their principles is that it is better to prevent waste than to treat or clean it up after it is formed. The opportunity to prevent it comes early in the design phase through intelligent materials, processes and product choices.

An example of using this principle is in choosing to use programmable logic devices (PLDs) over using discrete (separate) devices in an electronic design. The cost of early PLDs prohibited their use when compared to the cost associated with an equivalent number of discrete parts. Over the last 20 years however, advances in process technology have driven production costs down. Today, when comparing board area savings, operating performance, reliability, time to market, programmability, electro-magnetic interference, and design security in implementations using $74 \mathrm{xx}$ discrete parts to those using PLDs, the programmable devices tend to come out ahead. The underlying motivation in all of this boils down to cost. However, it is important to note that many of these factors benefit the environment and society as well. Replacing multiple discrete parts with a single PLD reduces resource usage, both in manufacturing and printed circuit board area, and reduces waste. The inherent reprogrammable nature of PLDs, permitting firmware upgrades of products in the field, increases product lifespan, keeping the technical "nutrients" out of the biosphere waste chain.

\section{PRINCIPLE 4: THE SUN IS THE EARTH'S ENERGY SOURCE}

Global energy needs have taken center stage in public policy, primarily because many developed nations rely on non-renewable sources like petroleum oil. We often discuss various energy "sources": oil, solar energy, hydroelectric power, wind. In reality, there is only one source - the sun. Oil can ultimately be traced back to the sun, which has stored energy in the form of carbon-hydrogen and carbon-carbon bonds over the course of millions of years. Hydroelectric and wind power are tied to heat transfer cycles that are driven by the sun.

Engineers can profoundly shift negative impacts caused by acquiring and consuming oil by designing for a sustainable energy source. By introducing the simple but profound idea that the sun is essentially our only true, renewable energy source, students approach the design process differently. For example, during the early stages of the design phase, the student may choose to use solar energy or solar-derived energy (e.g., photovoltaic) instead of a non-renewable source, such as oil or natural gas.

We are using this idea in our thermodynamics course, applied to the design of a local transport system that will displace the daily need for 6000 vehicles on our campus. The students involved in the design teams are aware of the fact that all nonsolar energy "sources" are non-renewable. As a result, their design decisions more fully consider the societal impacts of, for example, specifying gasoline-powered vehicles. 


\section{PRINCIPLE 5: OPTIMIZE RATHER THAN MAXIMIZE}

Within the U.S. popular culture, there is often an underlying assumption that bigger, faster, more, equate to better. In other words, there is a tendency toward maximization; improving a design means driving the design closer to the identified maxima. J. Benyus, author of Biomimicry: Biomimicry: Innovation Inspired by Nature,${ }^{14}$ promotes the idea of optimization over maximization. In other words, rather than assuming that a faster circuit is a better one, a designer may instead look for an optimal speed against other factors that should be considered (e.g., societal, political, ethical, health and safety, environmental and sustainability). As an example, a circuit designer could choose a slower clock speed in favor of reducing energy consumption. Oftentimes the increases in clock speed are more of a marketing advantage, appealing to the cultural idea that faster is better. With optimization as an orientation, perhaps a new marketing angle could emerge, such as a "greener" product.

This principle of optimization over maximization is also embedded in Anastas' and Zimmerman's 12 Principle of Green Engineering. ${ }^{13}$ Their principles discuss the fact that products should not be designed for immortality, but for an appropriate product cycle. The reality is that consumers rarely want a product to last forever. Optimization essentially amounts to challenging marketing assumptions that insist that more is better. An example of a product that has been maximized rather than optimized is graphite-fiber-reinforced composites. They are immortal, relative to the consumer market. They do not break down over time. This presents a problem; at the end of their life cycle, they cannot be reused, so they end up in landfills for what is expected to be thousands of years.

Our materials engineering sophomores are currently working on projects in a materials selection course which requires them to redesign an everyday product for optimum performance against the product's environmental and societal impact. For example, a group may redesign a cooking spatula. The assignment requires the students to engage in the engineering design activities that they would in any situation. However, the "optimization" mindset forces her to look beyond the one-dimensional concerns of economic performance.

\section{CHANGES IN STUDENT ATTITUDES}

We are currently in the initial stages of a study to measure changes in attitude within engineering students after being exposed to these principles. We tested a group of 28 engineering freshmen on their first day of college, asking them to state what they believe as the role of an engineer in society. Eighteen percent of the group made reference to engineers' role to help society. However, after a year-long experience in which we used various exercises involving the principles above, $79 \%$ of the students stated that they believed that the role was to apply their knowledge for the advancement and betterment of humanity. Although it is not clear that this change in perspective will result in socially responsible action, it is a measurable shift in the direction of awareness of their social responsibilities. 


\section{SUMMARY}

Socially responsible action lies at the very core of the engineering profession. In order to promote it, however, engineering curricula must go beyond the focus on technical skill; we believe that socially responsible action also requires an awareness of the needs and a willingness to provide for these needs. These key attributes can be promoted as a natural part of the curriculum. The global challenges provide inspiration for socially responsible action, but the awareness of the challenges must be coupled with guiding principles on which to take action. Drawing on the work of others, we have identified five principles that can be communicated in the natural course of engineering curricula: 1 . everything is connected; 2 . earth is a closed thermodynamic system; 3 . make responsible choices early in the design phase; 4 . the sun is the earth's energy source; and 5. optimize rather than maximize. Our preliminary results show that students exposed to these principles show a shift in attitude toward a greater awareness of social responsibility.

\section{REFERENCES}

1. National Society of Professional Engineers, "Code of Ethics for Engineering: Engineer's Creed," www.nspe.org/ethics/.

2. Colby, A., Kohlberg, L., Speicher, B. et al. (1987) The Measurement of Moral Judgment, vol. 1 \& vol. 2, Cambridge University Press, New York, NY.

3. Wackernagel, M., N.B. Schulz, D. Deumling, A. Callejas Linares, M. Jenkins, V. Kapos, C. Monfreda, J. Loh, N. Myers, R. Nargaard, and J. Randers (2002) "Tracking the Ecological Overshoot of the Human Economy," Proceedings of the National Academies of Sciences 99: 9266-9271.

4. Goodstein, David (2004) Out of Gas: The End of the Age of Oil, W.W. Norton and Company, New York, NY, p.128.

5. Boyd, D.R. (2001) Canada vs. the OECD: An Environmental Comparison, University of Victoria, Victoria, BC, p. 13.

6. The Association of University Leaders for a Sustainable Future, The Talloires Declaration (Washington, DC, 1990) available on-line at www.ulsf.org/programs_talloires_td.html.

7. Orr, D.W. (1994) Earth in Mind: On Education, Environment, and the Human Prospect, Island Press, Washington, DC, p. 27.

8. Capra, F. (2002) The Hidden Connections: A Science for Sustainable Living, Anchor Books, New York, NY.

9. Anderson, V. and L. Johnson (1997) Systems Thinking Basics: From Concepts to Causal Loops, Pegasus Communications, Inc., Waltham, MA.

10. Richmond, B. (1993) "Systems thinking: critical thinking skills for the 1990s and beyond," Systems Dynamics Review 9: 113-133.

11. For example, see J. Puckett, L. Byster, S. Westervelt, R. Gutierrez, S. Davis, A. Hussain and M. Dutta (2004) Exporting Harm: The High-Tech Trashing of Asia, The Basel Action Network and Silicon Valley Toxics Coalition, p. 3. (available at www.svtc.org/cleancc/pubs/technotrash.html)

12. U.S. Environmental Protection Agency. Office of Research and Development, Life Cycle Assessment: Inventory Guidelines and Principals. (1993): EPA/600/R-92/245.

13. Anastas, P. and J. Zimmerman (March 1, 2003) "Designing Through the 12 Principles of Green Engineering," Environmental Science and Technology, 95A-101A.

14. Janine M. Benyus (1997) Biomimicry: Innovation Inspired by Nature, Perennial. 